\title{
EUTROFIZAÇÃO NO RESERVATÓRIO DA UHE FOZ DO RIO CLARO (GO)
}

\author{
Pollyanna Faria Nogueira ${ }^{1}$ \\ João Batista Pereira Cabral ${ }^{2}$ \\ Susy Ferreira Oliveira ${ }^{3}$ \\ Isabel Rodrigues da Rocha ${ }^{4}$
}

RESUMO: O crescimento populacional tem ocasionado um aumento na demanda pelo uso dos recursos hídricos, e caracteriza-se como um dos principais responsáveis pela poluição dos corpos d'água. Outro fator é o aproveitamento dos cursos d'água para a geração de energia hidroelétrica entre as cidades de Jataí e São Simão, mudando as características físicas, químicas e biológicas dos recursos hídricos devido à transformação de um ambiente lótico para lêntico. $O$ presente artigo teve por objetivo avaliar o nível de estado trófico das águas do reservatório Foz do Rio Claro (GO), a partir da análise do índice do Estado Trófico (IET). Foram coletadas amostras de água em 23 pontos do reservatório, em quatro períodos distintos entre janeiro de 2013 e agosto de 2014. Os parâmetros avaliados foram: fósforo total (PT), transparência de Secchi (SEC) e clorofila " $a$ " (CHL). De modo geral considerara-se que as águas do reservatório estão passando de uma produção de nutrientes baixa para intermediária, classificando o reservatório para o IET em 25/01/2013 como mesoeutrófico, em 26/01/2014 como eutrófico e oligomesotrófico; 03/07/2013 mesoeutrófico e 03/08/2014, ultraoligotrófico, oligotrófico e mesotrófico.

Palavras-chave: qualidade da água, bacia hidrográfica, clorofila "a".

\section{EUTROPHICATION IN RESERVOIR FOZ DO RIO CLARO - BRAZIL}

ABSTRACT: Population growth has caused an increase in demand for the use of water resources, and is characterized as a major contributor to the pollution of water bodies. Keywords: Quality water, Basin, Chlorophyll-a; phosphorous. Another factor is the use of waterways for hydroelectric power generation between the cities of Jatai and São Simão, changing the physical, chemical and biological characteristics of water resources due to the transformation of a lotic to lentic. This article aims to assess the state trophic level of the reservoir waters Foz do Rio Claro (GO), from the analysis of the Trophic State Index (IET). Water samples were collected in 23 points of shell in four different periods between January 2013 and August 2014. The parameters evaluated were: total phosphorus (PT), Secchi transparency (SEC) and chlorophyll " $a$ " (CHL). In general it is considered that the water tank is flowing from a production intermediate to low nutrients, classifying the reservoir for the EIT on 25/01/2013 as mesoeutrófico on 26/01/2014 as eutrophic and oligomesotrófico; 03/07/2013 and 03/08/2014 mesoeutrófico, ultraoligotrófico, oligotrophic and mesotrophic.

Keywords: water quality, watershed, chlorophyll "a".

1. Universidade Federal de Goiás/REJ (pollypam@hotmail.com).

2. Universidade Federal de Goiás/REJ (jbcabral2000@yahoo.com.br).

3. Doutoranda PPGEO/IESA (susyufg@yahoo.com.br).

4. Universidade Federal de Goiás/REJ (isabel8720@gmail.com.br). 


\section{INTRODUÇÃO}

Segundo Agostinho et al., (2007), as represas artificiais são obras de engenharia que vem sendo construídas a aproximadamente 5.000 anos, de acordo com levantamentos realizados na Ásia e no Oriente Médio. No início do século XX surgiram centenas de grandes empreendimentos hidráulicos ao redor do mundo, onde a maioria foi construída entre as décadas de 60 e 90 e grande parte está localizada nos países asiáticos, principalmente na China, uma porção considerável esta distribuída na América do Norte, América Central e Europa Ocidental. Comparativamente, a América do Sul apresenta um número menor de empreendimentos hidráulicos, entretanto, nela estão situados alguns dos maiores do mundo.

No Brasil, as décadas de 60 e 70 podem ser consideradas o período de grandes construções de empreendimentos hidráulicos, principalmente para fins de produção de hidroeletricidade e abastecimento humano (TUNDISI, 2007). Muitos destes empreendimentos estão em atividade, produzindo inúmeros benefícios e impactos ambientais tanto locais como regionais.

Os empreendimentos hidráulicos conhecidos como reservatórios apresentam características intermediárias entre rios e lagos, espacialmente definidos em uma sequência horizontal (zonas lótica, de transição e lacustre) (THORNTON, 1990). Entretanto, em sistemas pequenos, rasos e com elevado tempo de residência, a zonação longitudinal é ausente, pois a coluna d'água sofre ação direta do vento e de outras turbulências como, por exemplo, as precipitações, as quais criam condições homogêneas e/ ou isotérmicas em praticamente todo o corpo d'água (NASELLI-FLORES e BARONE, 2003).

O processo de antropização nas bacias hidrográficas a partir do aumento das atividades humanas tem se tornado cada vez mais impactante em relação à qualidade das águas. $\mathrm{O}$ uso do solo é um importante fator que contribui para a degradação e acelera o processo de eutrofização de rios, lagos e reservatórios. Deste modo à deterioração da qualidade da água pode ser resultado dos fatores naturais de uma bacia hidrográfica, dos diferentes usos da terra e da pressão antrópica sobre os ambientes aquáticos.

Conforme Carlson (1990) e Lamparelli (2004), o Índice do Estado Trófico (IET) funciona como um registro das atividades humanas na bacia hidrográfica, fornecendo subsídios para a formulação de planos de manejo e gestão de ecossistemas aquáticos, por meio de estratégias que visem à sustentabilidade dos recursos hídricos. O IET tem por objetivo classificar corpos hídricos em diferentes graus de trofia, avaliando a qualidade da água quanto ao enriquecimento por nutrientes.

A bacia do rio Claro conforme estudos desenvolvidos por Cabral et al (2013), Rocha, Cabral e Braga (2014) apresenta um intenso uso antrópico com áreas urbanas, agrícolas (cultivo da cana-de-açúcar, milho e soja) e de pecuária (criação de gado), proporcionando a eliminação de efluentes domésticos e industriais para os cursos d'água, ocasionando alteração na dinâmica dos rios e reservatórios pelo aumento da poluição pontual e difusa que as atividades antrópicas proporcionam.

A escolha da Usina Hidrelétrica (UHE) Foz do Rio Claro como objeto de estudo se justifica devido aos processos antrópicos que ocorrem na bacia do rio Claro, onde foram implantadas 
três UHEs (Caçu, Barra dos Coqueiros, Foz do Rio Claro) e uma PCH (Irara) em modo fio d'água. Todos os empreendimentos localizam-se a montante do barramento sendo a usina de Foz do Rio Claro a mais próxima à foz do Rio Paranaíba.

A UHE Foz do Rio Claro encontra-se em funcionamento desde janeiro de 2010, a área de seu reservatório é de 7,69 km² e seu potencial energético é de 64,8 MW (Figura 01). Sua bacia hidrográfica está situada entre os municípios de São Simão e Caçu, no estado de Goiás, com uma área de aproximadamente $151 \mathrm{Km}^{2}$, ao sul da área do distrito de Itaguaçu (GO) na microrregião de Quirinópolis (GO).

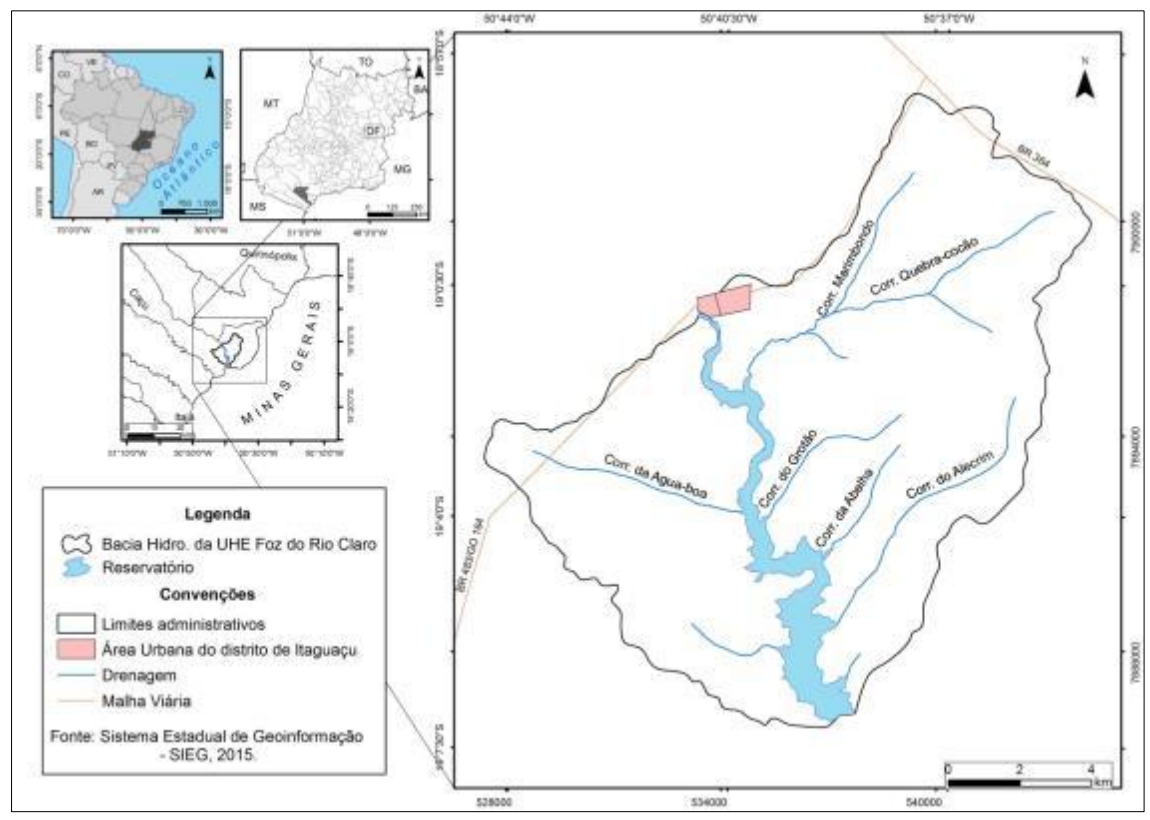

FIGURA 01: Localização da Bacia Hidrográfica da UHE Foz do Rio Claro. Fonte: Nogueira, P.F. Queiroz Junior, V.S. (2015).

\section{MATERIAL E MÉTODO}

Foram determinados 23 pontos de amostragem no reservatório da UHE de Foz do Rio Claro devido à sua extensão para se compreender a distribuição espacial e temporal dos nutrientes. As amostras de água foram coletadas nos primeiros $20 \mathrm{~cm}$ de profundidade, que segundo Esteves (1998) e Tundisi (2008) correspondem à camada mais superficial do corpo d'água (epilímnio) onde tende a ocorrer as maiores temperaturas, o que, juntamente com o aporte de nutrientes, aumenta a produtividade de organismos nas camadas superficiais.

Para determinação da CHL seguiu-se a proposta desenvolvida por Yunes e Araújo [s/d] com base em Mackinney (1941), Paranhos (1996) e Chorus (1999) que se baseia no cálculo da concentração de clorofila em $\mu \mathrm{g} . \mathrm{L}-1$,considerando as medições do espectrofotômetro, o volume de pigmentos extraídos e o volume filtrado, conforme apresentado na Equação 1.

Nos experimentos realizados, utilizou-se o Espectrofotômetro modelo UV - 1000A, com faixa de operação entre 320 a $1100 \mathrm{~nm}$ da Instrutherm:

Chl a $(\mathrm{mg} / \mathrm{L})=\underline{\text { A }} \underline{(663-750)} .12,63$ Vol. Extração $(\mathrm{mL}) .1000] /$ Vol filtrado $(\mathrm{mL})$ 
Onde:

- A: absorbância em 663 e 750 nm;

- 12,63: constante;

- Vol. Extração: volume de metanol utilizado; e,

- Vol. Filtrado: volume de água filtrada.

O procedimento para analise do PT foi realizado de acordo com o método Vanadomolibdico Fotocolorímetro, por intermédio do equipamento multiparâmetro de bancada da AT100 Alfakit, que segue a metodologia proposta pelo Standard Methods for the Examination of Water and Wastewater, 18th edition.

A transparência da água foi realizada a partir da metodologia do Disco de Secchi realizada in loco seguindo a proposta de Esteves (1998) onde a medida de transparência é obtida ao mergulhar o disco branco no lado oposto à sombra do barco, através de uma corda graduada.

Para a classificação dos Índices de Estado Trófico foi adotada a metodologia proposta por Lamparelli (2004). A finalidade IET é classificar corpos d'água em diferentes graus de trofia, ou seja, avaliar a qualidade da água quanto ao enriquecimento por nutrientes, de acordo com as formulas 1, 2, 3, 4, e Quadro 01.

Cálculo do IET para Lamparelli (2004):

$$
\text { - } \operatorname{IET}(S)=10\left[6-\frac{\ln S}{\ln 2}\right]
$$

(01) em que a transparência (S) é expressa em $\mathrm{m}$.

- $\operatorname{IET}(C L)=10\left[6-\frac{0,92-0,64(\ln C L)}{\ln 2}\right]$

(02) em que a clorofila (CL) é expressa em $\mu \mathrm{g} \cdot \mathrm{L}^{-1}$.

- $\operatorname{IET}(P T)=10\left[6-\frac{1,77-0,42(\ln P T)}{\ln 2}\right]$

(03) e o fósforo total (PT) é expresso em $\mu g . L-1$.

\begin{tabular}{|c|c|c|c|c|c|}
\hline & Estado Trófico & $\begin{array}{l}\text { IET } \\
\text { Total }\end{array}$ & $\begin{array}{c}\text { Clorofila } a \\
(\mu \mathrm{g} / \mathrm{L})\end{array}$ & $\begin{array}{c}\text { Fósforo total } \\
(\mu \mathrm{g} / \mathrm{L})\end{array}$ & $\begin{array}{c}\text { Transparência } \\
\text { (m) }\end{array}$ \\
\hline \multirow{6}{*}{$\begin{array}{l}\text { Lamparelli } \\
\text { (2004) }\end{array}$} & Ultraoligotrófico & $\leq 47$ & $\leq 1,17$ & $\leq 8$ & $>2,4$ \\
\hline & Oligotrófico & $47<\mathrm{EET} \leq 52$ & $1,17<C l \leq 3,24$ & $8<\mathrm{FT} \leq 19$ & $2,2>S \geq 1,7$ \\
\hline & Mesotrófico & $52<\mathrm{IET} \leq 59$ & $3,24<C l \leq 11,03$ & $19<\mathrm{FT} \leq 52$ & $1,7>S \geq 1,1$ \\
\hline & Eutrófico & $59<\mathrm{IET} \leq 63$ & $11,03<\mathrm{Cl} \leq 30,55$ & $52<\mathrm{FT} \leq 120$ & $1,1>S \geq 0,8$ \\
\hline & Supereutrófico & $63<\mathrm{IET} \leq 67$ & $30,55<\mathrm{Cl} \leq 69,05$ & $\begin{array}{c}\leq \\
120<\mathrm{FT} \leq 233\end{array}$ & $0,8>S \geq 0,6$ \\
\hline & Hipereutrófico & $>67$ & $>69,05$ & $>233$ & $<0,6$ \\
\hline
\end{tabular}

QUADRO 01 - Equivalência do IET para as medidas das variáveis de fósforo, clorofila $a$ e transparência em reservatórios segundo Lamparelli (2004).

Fonte: Lamparelli (2004). 


\section{RESULTADOS E DISCUSSÃO}

\section{- Clorofila " $a$ " (CHL)}

Segundo Henry e Simão, (1990) a produtividade primária, que pode ser expressa indiretamente através da concentração da clorofila-a é controlada pela ação de fatores como luz subaquática e nutrientes.

De acordo com os dados apresentados no Gráfico 01 e na Figura 02, o Índice de Estado Trófico para a CHL espacialmente e temporalmente, classifica as águas do reservatório como supereutrófica para os quatro períodos avaliados. A concentração dessa variável está acima do estabelecido pela legislação, pois segundo a Resolução CONAMA 357/2005 para que o corpo hídrico seja enquadrado na Classe 1, e 2 os valores máximos permitidos para este parâmetro são $10 \mu \mathrm{g} / \mathrm{L}$ e $30 \mu \mathrm{g} / \mathrm{L}$, respectivamente.

Possivelmente essa supereutrofização pode ter sido ocasionada pela quantidade de matéria orgânica em decomposição no reservatório, pelo lançamento de efluentes da área urbana do distrito de Itaguaçu e PT de áreas agrícolas na bacia, pois conforme Von Sperling (2005) em reservatórios situados em proximidades de centros urbanos ou de áreas agrícolas comumente se verifica uma progressiva acumulação de plantas aquáticas e um processo de eutrofização acelerado.

Segundo Lamparelli (2004) ambientes supereutróficos são corpos d'água com elevada produtividade em relação às condições naturais, baixa transparência, em geral afetados por atividades antrópicas nos quais ocorrem com frequência alterações indesejáveis na qualidade da água como a ocorrência de episódios de florações de algas e interferências nos seus múltiplos usos.

Esse resultado de supereutrofização das águas do reservatório de Foz do Rio Claro pode ter como consequência uma alteração das características químicas e físicas do meio, podendo trazer conseqüências negativas para o ecossistema aquático como a morte de diversos organismos.

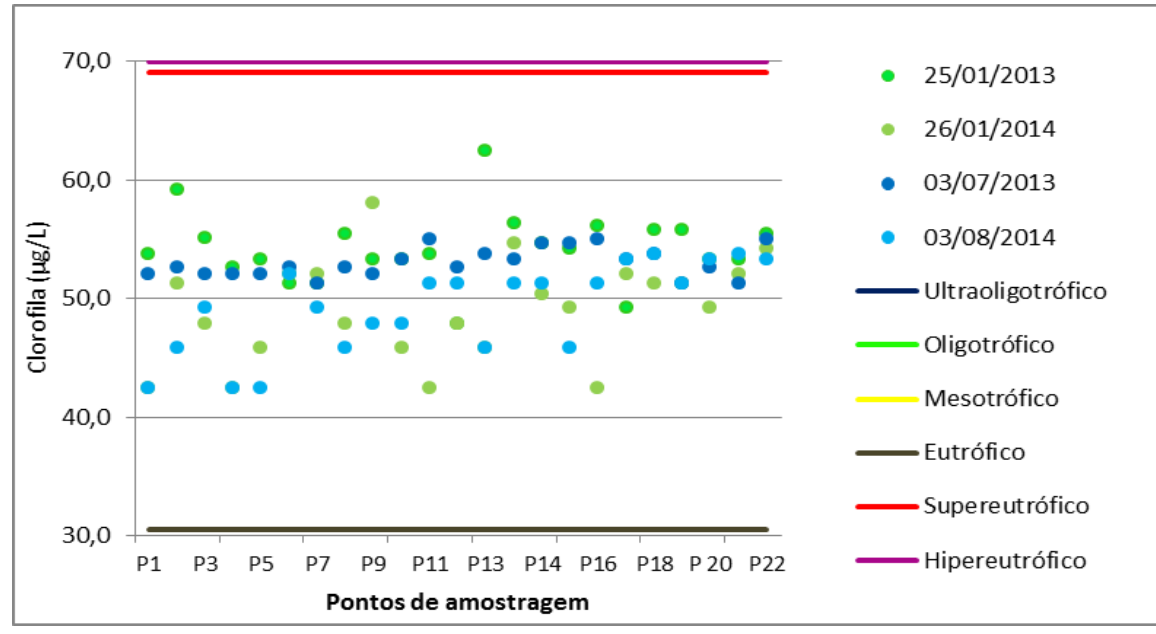

GRÁFICO 01: IET da Clorofila a $(\mu \mathrm{g} / \mathrm{L})$

Organização: Nogueira, P.F (2014). 




FIGURA 02: Clorofila " $a$ " (CHL).

Fonte: Nogueira, P.F. Queiroz Junior, V.S. (2015).

Organização: Nogueira, P.F (2014).

\section{- Fósforo (PT)}

Segundo Tundisi e Matsumura Tundisi, (2008) Nutrientes como o fósforo atualmente tem sua disponibilidade aumentada em função do uso de fertilizantes na agricultura e esgotos urbanos e industriais das aglomerações humanas sem tratamento adequado.

Conforme os resultados obtidos (Gráfico 02 e Figura 03) o IET do "PT" classificam as águas do reservatório entre eutrófica e mesotróficas onde estas categorias de classificação podem ser consideradas de produtividade intermediária passando para alta.

Nos meses de janeiro de 2013 e 2014 o corpo d'água apresenta alta concentração de PT em todo reservatório devido à influência da precipitação, proporcionando o carregamento de nutrientes. Já nas coletas de Julho de 2013 e agosto de 2014 é possível verificar que o ambiente do reservatório é influenciado pela velocidade de escoamento da água, largura e profundidade, pois entre o início do reservatório e o córrego do Grotão ele é classificado 
como eutrófico e este trecho apresenta característica de ambiente lótico, enquanto entre o córrego Grotão e o barramento da usina é classificado como mesotrófico e apresenta características de ambiente de lago, baixa velocidade de escoamento da água, distancia entre as margens superiores ao inicio do reservatório e baixa concentração de sedimentos em suspensão.

Os valores estabelecidos para o PT em ambiente intermediário de acordo com a resolução CONAMA 357/2005, com tempo de residência entre 2 e 40 dias é de até 0,025 mg/L para classe $1,0,030 \mathrm{mg} / \mathrm{L}$ para a classe 2 e de $0,075 \mathrm{mg} / \mathrm{L} \mathrm{P}$ para a classe 3 . Com base nisso os valores de PT detectados para o reservatório Foz do rio Claro (entre 0,010 a 0,090 mg/L), encontram-se acima dos padrões estabelecidos em sua maioria para classe 2 e 3.

No desenvolvimento da pesquisa para Foz do rio Claro foi verificado que no período chuvoso os valores de PT apresentaram-se elevados, caracteristica encontrada também por Gomes et. al. (2010), quando verificaram no rio Catolé BA que as concentrações de fósforo foram maiores na coleta realizada no início de julho, período este caracterizado por grande quantidade de chuvas (no estado da Bahia), as quais podem ter favorecido o carreamento deste elemento para o interior do rio.

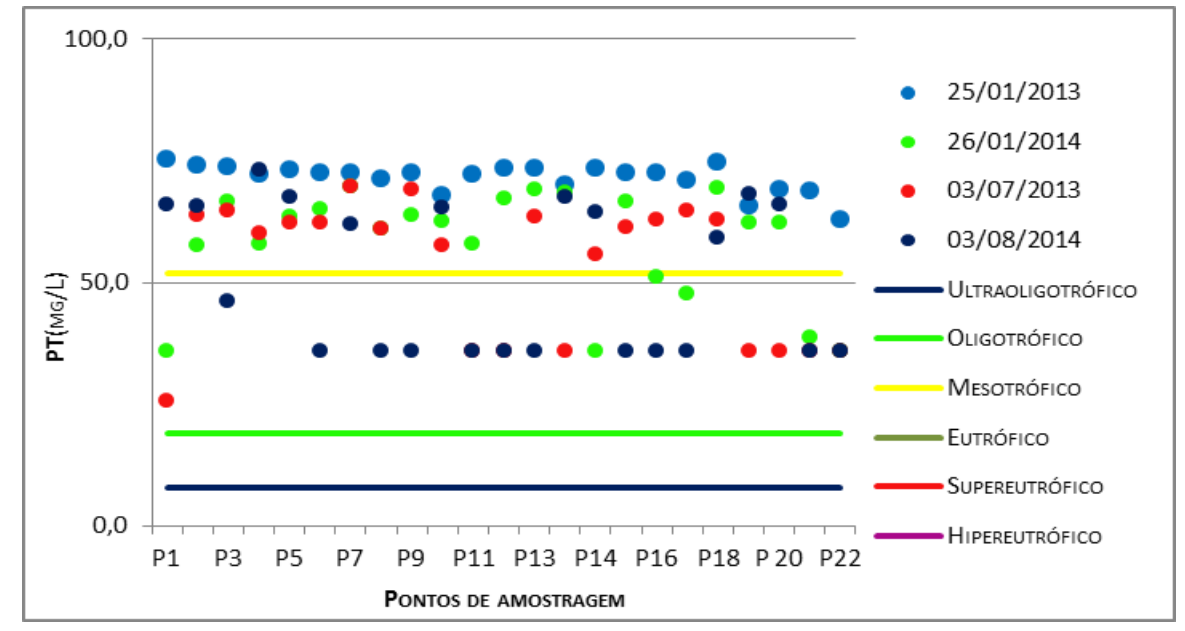

GRÁFICO 02: IET PT $\mu \mathrm{g} / \mathrm{L}$

Organização: Nogueira, P.F (2014). 


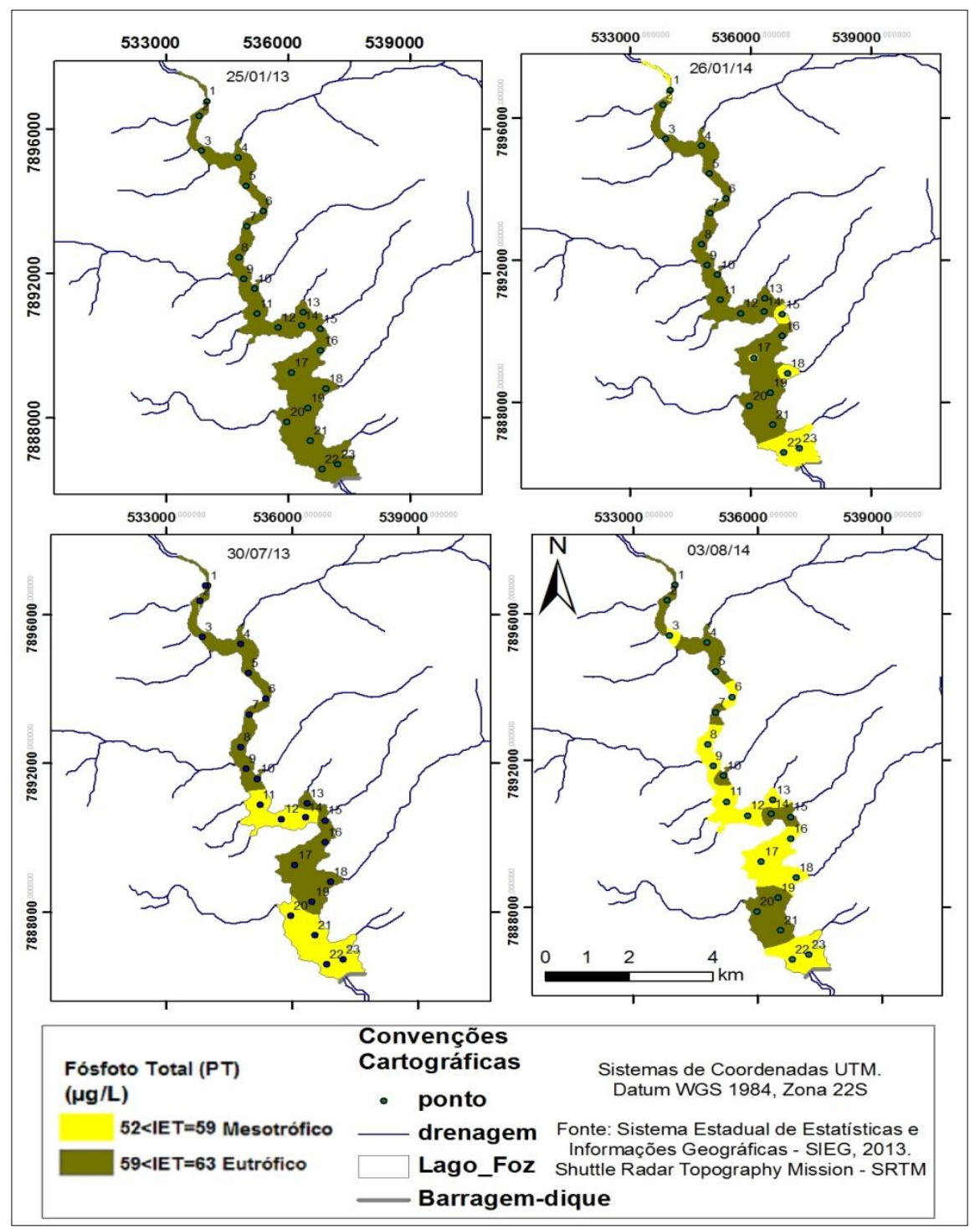

FIGURA 03: Fósforo Total (PT).

Organização: Nogueira, P.F (2014).

Segundo Ling e Nyanti Lee (2013), as concentrações de fósforo no reservatório de Batang Malásia, no período chuvoso ficaram entre 24,90 a $38,59 \mathrm{mg} / \mathrm{L}$, enquanto que no período menos chuvoso a concentração foi de 45,94 a $67.28 \mathrm{mg} / \mathrm{L}$, situação inversa ao que ocorreu nas água de Foz do Rio Claro pois as águas de Batang são utilizadas além da produção de energia para aquicultura demonstrando que o PT tem influência da precipitação e dos índices de fração orgânica existente em um ambiente.

Os resultados do PT podem ter sido influenciados pelo uso da terra na bacia que tem uma grande área reservada à pecuária e ao cultivo da cana de açúcar, e também em partes do reservatório é possível verificar a falta da vegetação nativa nas margens do reservatório fazendo com que o carreamento de sedimentos para o curso d'água seja mais elevado nesses pontos. 
Conforme Chukwu e Odunzeh, (2006); Shekhar et al, (2008).atividades antrópicas são os principais agentes causadores do aumento de nutrientes como fosfatos, e finalmente, levam a eutrofização

Segundo Lamparelli (2004) a importância da avaliação do fósforo é indiscutível, uma vez que ele é na maioria dos ambientes o fator limitante para este processo. Sendo assim o fósforo disponível é um dos fatores mais importantes na regulação da produtividade do sistema.

\section{- Transparência da água a partir do disco de Secchi (SEC)}

Ribeiro Filho et al (2010), destacam que a transparência da água influencia fortemente o estado trófico de habitats aquáticos e a penetração da luz determina o desenvolvimento de fitoplâncton como uma consequência de enriquecimento no reservatório.

Quanto aos valores obtidos para SEC, a água do reservatório demonstra uma variação significativa conforme pode ser observado no Gráfico 03 e Figura 04, sendo possível detectar vários compartimentos no reservatório quanto às classes do IET - SEC, classificando as águas do reservatório entre ultraoligotrófica e hipereutrófica.

O SEC para o período chuvoso oscilou entre $0,24 \mathrm{~cm}$ a $0,66 \mathrm{~cm}$ com média de $0,38 \mathrm{~cm}$ para $25 / 01 / 13$, e para 26/01/14 de 0,88 a 1,3 m com média de $1,03 \mathrm{~m}$. Ao se avaliar a Figura 05 é possível verificar que o aumento da transparência no corpo d'água ocorreu ao longo do eixo longitudinal do reservatório, fato semelhante aos estudos desenvolvidos por Meirinho (2010), em um braço do reservatório do Complexo Billings - SP, e Cabral et al (2009) para o reservatório de cachoeira Dourada.

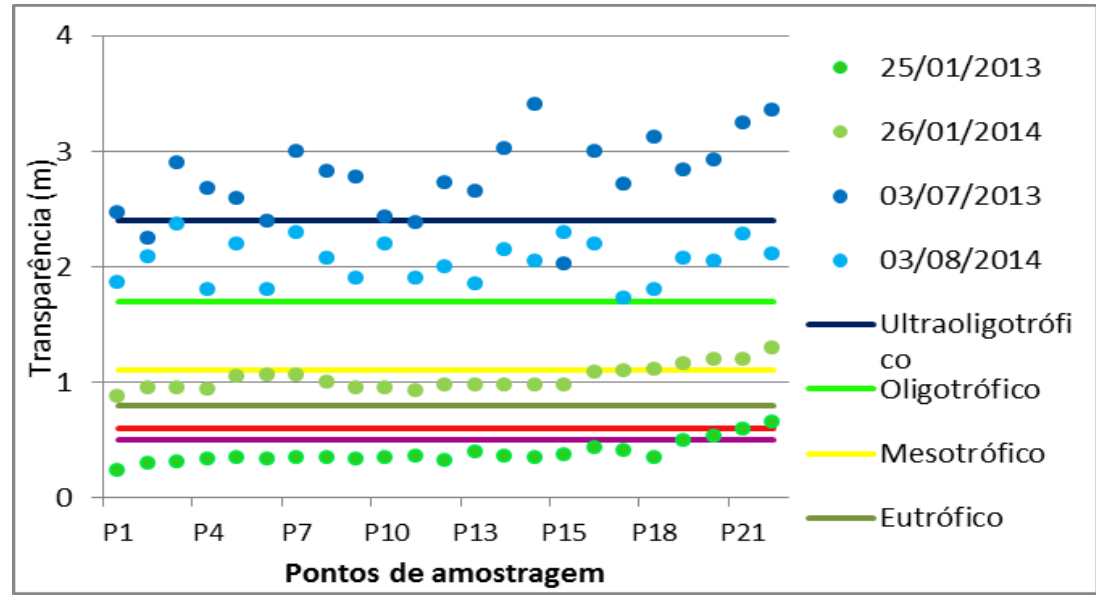

GRÁFICO 03 - IET do Disco de Secchi (m)

Organização: Nogueira, P.F (2014). 


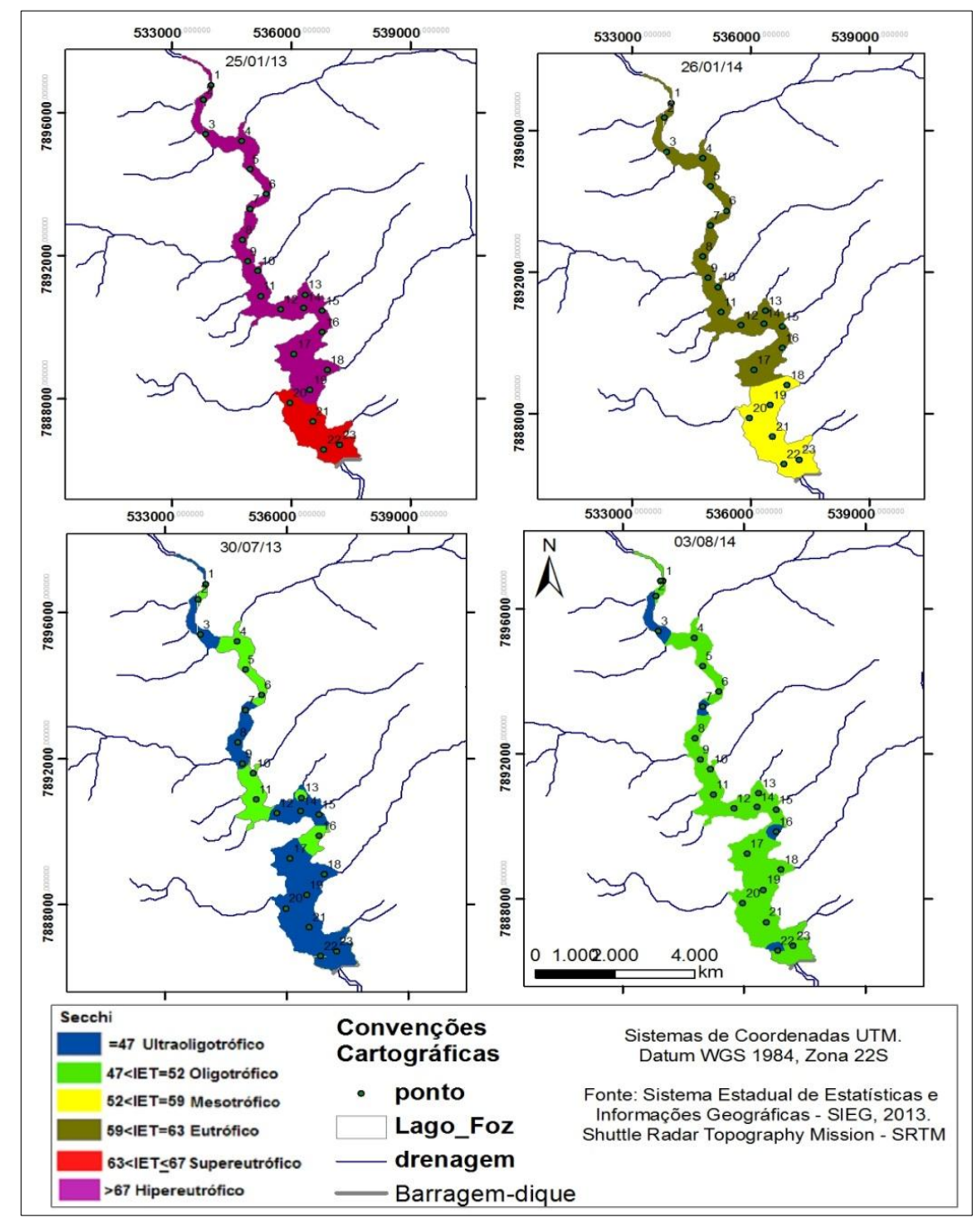

FIGURA 04: Disco de Secchi

Organização: Nogueira, P.F (2014).

Para o período considerado com baixo índice de chuva a transparência foi elevada em comparação com o período chuvoso. Para 30/07/13 oscilou de 2,01m a 3,41 m com uma média de 2,77 m, em 03/08/14 de 1,73 m a 2,37 $\mathrm{m}$ com média de 2,04 $\mathrm{m}$, podendo ser verificado uma visibilidade maior da água para este período. Silva et al (2009) obteve para o reservatório de Peti resultados semelhantes aos de Foz do rio Claro apresentando redução da transparência no período chuvoso que em muitos pontos chegou a $0,5 \mathrm{~m}$ e no período de estiagem chegou a $1,5 \mathrm{~m}$.

Em termos gerais a transparência da água foi considerada baixa nos períodos chuvosos (dia $25 / 01 / 2013$ e $26 / 01 / 2014$ ) (foto $5 A$ ) e alta nos períodos menos chuvosos (30/07/2013 e 03/08/2014) (Foto 5B) Fato semelhante aos resultados obtidos por Saxena (2012) para o reservatório de Raipur na Índia. 



FIGURA 05: Transparência da água conforme as estação chuvosa e menos chuvosa: A (janeiro / 2013), B (julho de 2013).

Organização: Nogueira, P.F (2014).

\section{- Índice do estado trófico (IET)}

A eutrofização de um corpo de água baseia se em um aumento excessivo de nutrientes na água, fato que pode ser causado por carreamento de fertilizantes agrícolas, águas pluviais e detergentes para o corpo d'água.

Conforme pode ser observado no Gráfico 04 e na Figura 06, o IET classifica as águas do reservatório como Mesoeutrófica (para 25/01/13), com destaque para o ponto 13 onde aparece a classe supereutrófica. Este resultado pode ser influenciado pelo córrego da abelha que fica bem próximo ao ponto de coleta e se encontra em uma área de agricultura, podendo estar carreando para o reservatório materiais contaminantes como fertilizantes agrícolas.

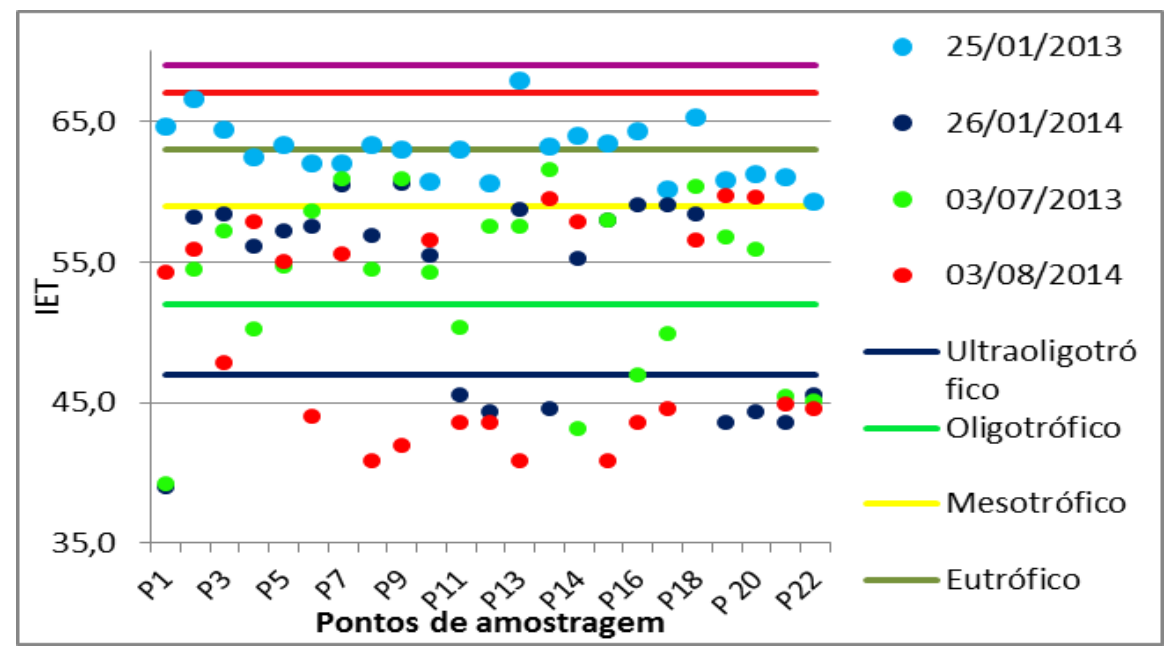

GRÁFICO 04 - (IET) Indice de Estado Trófico

Organização: Nogueira, P.F (2014). 


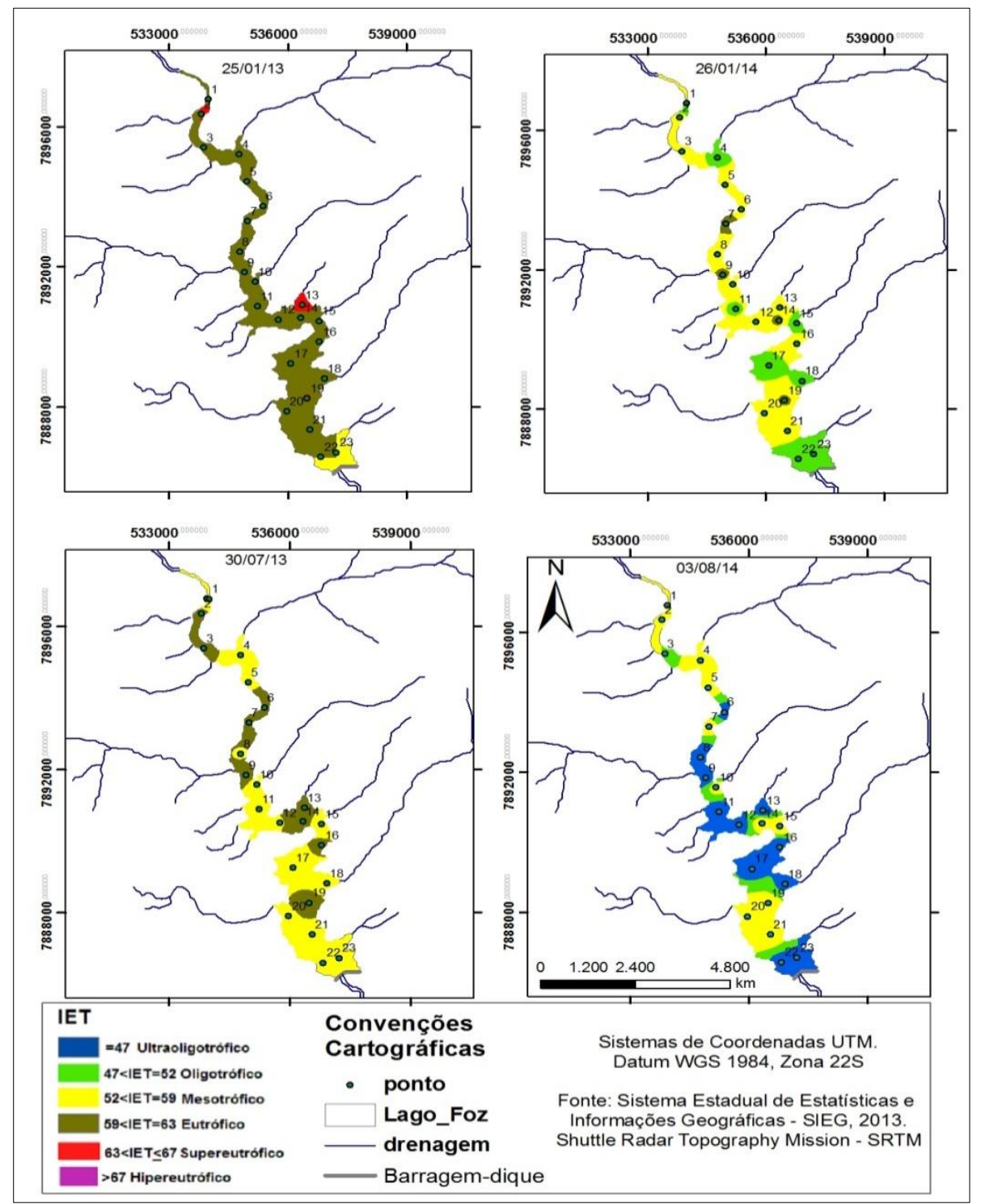

FIGURA 06: (IET) Índice do Estado Trófico.

Organização: Nogueira, P.F (2014).

Ribeiro Filho et al. (2013) em pesquisa no reservatório de Itaipu observaram que os resultados do índice de estado trófico (IET) mostraram que as zonas fluviais e as zonas de transição apresentaram um grau trófico mais elevado podendo ser relacionado com o maior aporte de nutrientes (poluição difusa) fato semelhante ocorreu para o reservatório Foz do rio Claro.

Para o período chuvoso (de 26/01/14) o IET classificou as águas do reservatório como eutrófica e oligomesotrófica. Resultado que pode ser influenciado pelo maior carreamento de sedimentos para o reservatório neste período, em que a classe eutrófica aparece em dois pontos distintos. No ponto 7 que é uma região onde o curso do rio se torna estreito podendo estar acumulando materiais das margens e no ponto 9 com influência de dois afluentes um em cada margem que podem carrear sedimentos/nutrientes para 0 reservatório. 
Em 30/07/13, de acordo com as classes do IET, as águas do reservatório foram classificadas como Mesoeutrófica, indicando corpos de água passando de uma produtividade intermediária para alta. Em 03/08/14 os valores obtidos foram os mais baixos e o IET classificou as águas do reservatório como ultraoligotrófica, oligotrófica e mesotrófica, podendo verificar-se que o reservatório esta passando para uma produção intermediária, uma vez que para todos os campos a classe mesotrófica aparece, ressaltando que o reservatório tem apenas cinco anos de funcionamento e uma área $7 \mathrm{~km}^{2}$.

De acordo com os dados levantados na pesquisa é possível supor para as águas do reservatório que a produção de nutrientes pode causar possíveis implicações para a qualidade da água, pois conforme a estação do ano (período chuvoso ou menos chuvoso) altera-se os níveis de eutrofização da água, fato observado por Saxena (2012) para o reservatório de Raipur - İndia. Zanata (1999) e Minillo (2005) apontaram que a precipitação e a poluição difusa são os fatores que melhor explicam as mudanças no estado trófico em reservatórios.

Outro fator a ser levado em consideração é a disponibilidade de radiação sobre a lamina d'água, pois no centro oeste assim como em outros países tropicais pode ocorrer até 14 horas de luz disponível, favorecendo com isto a biomassa de fitoplâncton que começa a aumentar à medida que a temperatura da água e da luz aumenta assim como a disponibilidade de nutrientes na forma dissolvida para uso do fitoplâncton. Isto é favorecido pela presença inadequada na bacia de drenagem de diversas pontes poluidoras (VALE et. al. 2007).

Segundo Saxena (2012) o estado trófico é definido como o peso total da biomassa num dado corpo d'água no momento da medição. Nos corpos de água doce os nutrientes desempenham um papel importante com a sua entrada excessiva e levam à eutrofização.

\section{CONCLUSÃO}

O IET para a CHL classificou as águas do reservatório como supereutrófico para os quatro períodos avaliados.

Para o IET do PT as águas do reservatório foram classificadas como mesotrófica e eutrófica, indicando que o ambiente esta passando de uma produção intermediária para alta, ocasionada pelo enriquecimento por nutrientes.

O IET para o SEC é influenciado pelas precipitações que ocorrem na bacia e carreamento de sedimentos/nutriente para o corpo d'água. Os menores valores de transparências foram detectados no período chuvoso (25/01/13 e 26/01/14) e o maior no período menos chuvoso (30/07/13 e 03/08/14), indicando que esta analise é fortemente influenciado pelos fatores climáticos.

O IET em 25/01/13 classificou as águas do reservatório como eutrófico e mesoeutrófico e em 26/01/14 como mesotrófico e oligotrófico. Para os períodos com baixo índice de chuvas os resultados foram em 30/07/13 mesotrófico e eutrófico, em 03/08/14 mesotrófico, ultraologtrófico e oligotrófico, indicando que o ambiente do reservatório esta passando por uma mudança de produção de nutrientes para classes mais elevadas de eutrofização. 
Com base nos dados obtidos verificou-se que a qualidade da água do reservatório da UHE de Foz do Rio Claro pode estar comprometida por apresentar valores elevados para a eutrofização, quando se considera que o tempo de construção do reservatório é de apenas cinco anos.

\section{BIBLIOGRAFIA}

AGOSTINHO, A.A., GOMES, L.C. PELICO, F.M. Ecologia e manejo de recursos pesqueiros em reservatórios do Brasil. Editora da Universidade Estadual de Maringá, Maringá. 501 p. 2007.

BRASIL. Conselho Nacional de Meio Ambiente. Resolução no 357 de 17 de março de 2005. Dispõe sobre a classificação dos corpos de água e diretrizes ambientais para o seu enquadramento, bem como estabelece as condições e padrões de lançamento de efluentes, e da outras providências. Disponível em: < http://www.mma.gov.br>. Acesso em 15/05/ 2014.

CARLSON, R. E. A trophic state index for lakes. Limnology and Oceanography, v.22 (2), p. 361 - 369. 1977.

CABRAL, J. B. P., FERnANDES, L. A, BECEgATO, V. A. SILVA, S. A. da Concentração de Sedimentos em Suspensão: Reservatório de Cachoeira Dourada- GO/MG, Brasil. Mercator (Fortaleza. Online). , v.8, p.233 - 253, 2009.

CABRAL, J. B. P. WACHHOLZ, F., BECEGATO, V. A., NASCIMENTO, E. S. Diagnóstico Hidrossedimentológico do Reservatório da UHE Caçu - GO. Geofocus (Madrid). , v.13, p.25 37, 2013.

CHORUS, I; BARTRAM, J. Toxic cyanobacteria in water: a guide to their public health consequences, monitoring and management. Londres: WHO/UNEP, 1999. Disponível em: $<$ http://www.who.int/water sanitation health/resourcesquality/toxcyanobacteria.pdf $>$ Acesso em: 20 abril. 2013.

CHUKKWU, L.O; ODUNZEH, C.C. Relative toxicity of spent lubricant oil and detergent against benthic macro-invertebrates of a West African estuarine lagoon. Journal of Environmental Biology, 27, 479-484. 2006.

ESTEVES, F. de A. Fundamentos de limnologia. 2a ed. Rio de Janeiro: Interciência, 548p. 1998.

GOMES, D. P. P.; BARROS, F. M.; BARRETO L. V.; ROSA R. C. C.; TAGLIAFERRI, C. Avaliação do estado trófico para o rio Catolé-BA em diferentes épocas do ano. Enciclopédia Biosfera, Centro Científico Conhecer, v.6, N.11; 2010.

HENRY, R; SIMÃO, A. C. Aspectos sazonais da liberação potencial por $\mathrm{N}, \mathrm{P}$ e Fe no fitoplâncton na represa de Barra Bonita (Rio Tietê, SP). Revista Brasileira de Biologia = Brazilian Journal of Biology, vol. 48, no. 1, p. 1-14. 1990.

LAMPARELLI, C.M. Graus de Trofia em Corpos d'água do Estado de São Paulo: Avaliação dos Métodos de Monitoramento. São Paulo, 2004. Tese (Doutorado em Ciências na Área de Ecossistemas Terrestres e aquáticos) - USP. 2004. 2004.

LING, T.Y E NYANTI, L. Phosphorus in Batang Ai Hydroelectric Dam Reservoir, Sarawak, Malaysia. World Applied Sciences Journal. ISSN 1818-4952. IDOSI Publications, 2013.

LOPES, A.G.D. Estudos da comunidade fitoplanctônica como bioindicador de poluição em três reservatórios em série do parque Estadual das Fontes do Ipiranga (PEFI), São Paulo, SP. 137 f. Dissertação (Mestre em Saúde Pública) Universidade de São Paulo, São Paulo, 2007.

MACKINNEY, G. Absorption of light by chlorophyll solutions. The Journal Biological Chemistry, v. 140, p. 315-322, 1941. 
MEIRINHO, P. do A. Compartimentalização da comunidade zooplanctônica em reservatório tropical urbano eutrofizado (braço Rio Grande, Complexo Billings,SP). 96 f. Dissertação (Mestrado em Ciências), Universidade de São Paulo, 2010.

MINILLO, A. Análise da distribuição, densidade e toxicidade de florações de cianobactérias e suas toxinas nos reservatórios do Médio e Baixo rio Tietê (SP) e relação com as características limnológicas do sistema. São Carlos: Universidade de São Paulo. 394 p. Tese de Doutorado em Engenharia Ambiental. 2005.

NASELLI. F, L; BARONE, R. Steady-state assemblages in a Meditarranean hyperthophic reservoir. The role of Microcystis ecomorphological variability in a maintaining na apparent equilibrium. Hydrobiologia 502:133-143. 2003.

RIBEIRO FILHO, R. A. A, PETRERE JUNIOR, M.B, C. BENASSI, S.F. D. PEREIRA, J.M.A.A. Itaipu Reservoir limnology: eutrophication degree and the horizontal distribution of its limnological variables. Braz. J. Biol., vol. 71, no. 4, p. 889-902. 2011.

RIBEIRO FILHO, R. A. A. PEREIRA, J. M. DE A. PETRERE JúNIOR, M. B. BENASSI, S. F. Eutrophication Indexes Used as Fish Production Parameters in the Itaipu Reservoir (Brazil). Journal of Environmental Protection, 4, 151-178. 2013.

ROCHA, H.M, CABRAL, J. B. P., BRAGA, C.C; Avaliação Espaço-Temporal das Águas dos Afluentes do Reservatório da UHE Barra dos Coqueiros/Goiás. Revista Brasileira de Recursos Hídricos. , v.19, p.131 - 142, 2014.

SAXENA, M. Water quality and trophic status of Raipur reservoir in Gwalior, Madhya Pradesh. Journal of Natural Sciences Research. Vol.2, N.8, 2012.

SHEKHAR, T.R.S., B.R. KIRAN, E.T. PUTTAIAH, Y. SHIVARAJ. K.M. MAHADEVAN. Phytoplankton as index of water quality with reference to industrial pollution. Journal of Environmental Biology, 29, 233-236. Shiddamallayya, N. and M. Pratima (2008). Impact of domestic sewage on freshwater body. Journal of Environmental Biology, 29, 303-308. 2008.

SILVA, A. P. de S. DIAS, H. C. T. BASTOS, R. K. X. SILVA, E. Qualidade da Água do Reservatório da Usina Hidrelétrica (UHE) de Peti, Minas Gerais. R. Árvore, Viçosa-MG, v.33, n.6, p.10631069, 2009.

VON SPERLING, M. Introdução à qualidade das águas e ao tratamento de esgotos. DESAUFMG, 2005.

THORNTON, W. K. Perspectives on reservoir limnology. In: THORNTON, K. W.; KIMMEL, B. L. e PAYNE, E. F. eds. Reservoir limnology: ecological perspectives. New York, John Wiley e Sons. p.1-13. 1990.

TUNDISI, J. G. Reservatórios como sistemas complexos: teorias, aplicações e perspectivas para usos múltiplos. In: HENRY, R. (Ed.) Ecologia de reservatórios: estrutura, função e aspectos sociais. Botucatu: FUNDIBIO. p. 19-38. 2007.

TUNDISI, J. G.; MATSUMURA TUNDISI, T. Limnologia. São Paulo: Oficina de Textos. 632 p. 2008.

VALE, A. C. M. DO. NOGUEIRA, I. S. AGUIAR M. DO A. A. Análise das Variáveis Físico-químico e da Biomassa Fitoplanctônica no Reservatório de Serra da Mesa. I Simpósio de Recursos Hídricos do Norte e Centro-oeste. 2007.

YUNES, J. S; ARAÚJO, E. A. C. Protocolo para análise de clorofila-a na água. Rio Grande do Sul: Unidade de Pesquisa em Cianobactérias da Fundação Universidade Federal de Rio Grande. [s/d].

\begin{tabular}{l|l|}
\hline Artigo submetido em & $10 / 02 / 2015$ \\
\hline Artigo aceito em & $23 / 06 / 2015$ \\
\hline
\end{tabular}

